\title{
Relating the Bubble Density to the Heat Transfer in Pool Boiling Processes of Surfactant Solutions
}

\author{
Khaled M.K. Pasha
}

Mechanical Power Department, Modern University, Cairo 11431, Egypt

Corresponding Author Email: khmki1@yahoo.com

https://doi.org/10.18280/ijht.370323

Received: 28 March 2019

Accepted: 30 August 2019

\section{Keywords:}

heat flux, tube, bubbles, surfactant concentration

\begin{abstract}
During a pool boiling process, the bubble distribution plays an essential role in the heat transfer enhancement. In the present work, a controllable test rig was prepared to investigate the heat flux and superheat temperature in a nucleate pool boiling process. Aqueous solutions of three surfactants were tested on three heated tubes that are made of brass, aluminum, and stainless steel with almost the same surface roughness. The investigated surfactants are; TRITON X100, SLES, and SDS, each one was tested at concentrations; 0, 100, 400, 700, 1000, 1300 , 1600 and $1900 \mathrm{ppm}$. For each case, the measured superheat temperatures and their corresponding heat fluxes and physical properties of the surfactant solution are fed into suitable relations. Consequently, correlations could be deduced to relate the heat flux to the bubble distribution, the superheat temperature and the concentration of different surfactant solutions. The results showed that, for all cases, the density of bubble distribution increased with the superheat temperature, the heat flux, and the surfactant concentration. For TRITON-X, the bubble distribution increased considerably with the surfactant concentration until the range of values between 400 and 700 ppm, and beyond this range, this rate of increase started to decay.
\end{abstract}

\section{INTRODUCTION}

The heat transfer from a surface to a single phase liquid depends mainly on the convection mechanism. But, when a phase change occurs during the boiling process, the bubble behavior produces an additional heat transport mechanism. The heat transfer in a boiling process is greatly affected by the bubbles behaviour (merging, frequency, growth, detaching, departure, coalescence, and age. The bubbles formation and activities constitute a major part of the heat transfer enhancement. The bubble behavior is affected by many factors which include the superheat temperature, the dynamic and equilibrium surface tensions, the liquid properties, the gravity, and any other force fields. These are beside the other effects from the physisorption and electro-kinetics actions at the liquid-solid interface and the Marangoni effect [1]. In phasechange processes, the primary mechanisms may be related to the liquid-vapor interfacial tension, and surface wetting at the solid-liquid interface. At the micro-scale, and during nucleation and bubble growth, the transient transport mechanisms at the solid-liquid-vapor interface can be attributed to the thin-film spreading and the micro-layer evaporation. But the major effect occurs at the macro-scale where, the heat transport is governed by the bubble growth, distribution, and dynamics; (bubble translation, coalescence, collapse, and break-up) [2,3].

Adding surfactant leads to a considerable improvement in the hydrophilic mechanism that affects the bubble dynamics and accordingly, enhances the pool boiling heat transfer. With the nucleation of a vapor bubble and during its subsequent growth, the diffusion of surfactant molecules, and their adsorption rates at the interface govern the extent of dynamic surface tension. The relation between the amount of additive and the reduction in surface tension is not linear, but asymptotic [2-3]. Toshiaki et al. [4] tested the surface tension for alcohol/water mixtures, and the alcohol mass fraction ranged from 0 to 1 and added Perfluoroalkyl to these mixtures at concentrations ranged from 0 to $5000 \mathrm{ppm}$. They reported that the surface tension decreased with the concentration until a mass fraction of 0.5 and beyond this value, the reduction rate decreased considerably to approach the value of $10 \mathrm{mN} / \mathrm{m}$. Suryanarayana et al. [5] investigated the variation of SDS concentration, (Sodium Dodecyl Sulfate) which is one of the surfactants used in the present work. They reported a heat transfer enhancement of about $73 \%$ for a concentration of 700 $\mathrm{ppm}$ and heat flux of $400 \mathrm{~kW} / \mathrm{m}^{2}$. For the same conditions and with the increase in concentration, the surface tension may decrease asymptotically, while the viscosity continues to increase [6]. When investigating the boiling process of aqueous solutions of surfactants; (SLS), TRITON X-100, and SDS. A considerable reduction in surface tension occurred. This reduction leads to a higher nucleation site density. And the bubble departure frequency was higher than that of pure water [7-9]. This, in turn, inhanced greatly the heat transfer process. Another investigation for the SLS aqueous solution exhibited an optimum boiling heat transfer augmentation of about $66.27 \%$ [10]. Zicheng [11] investigated the nucleate pool boiling heat transfer characteristics for different aqueous surfactant solutions; $99 \%$ sodium dodecyl sulfate (SDS) and TRITON X-114. He observed a reduction in surface tension and changes in the bubbles contact angles for a range of heat flux (24.7-109.1 kW/m²) and mass concentrations (50-8000 ppm for SDS and 20-1000 ppm for TRITON X-114). Adding surfactant enhances the force of repulsion resulting from the interaction of surfactants adsorbed at the interface region and helps the bubbles to leave the surface carrying more heat [12].

From the above, it is clear that, the addition of surfactant to the boiling water leads to an enhancement in the bubble 
density and activity, which in turn, leads to an enhancement in the heat transfer process.

In the present work, we intended to achieve a formula that relate the surfactant concentration to the bubble density and the heat transfer. This could be accomplished by;

1) Experimental investigation of the superheat temperature and heat flux in the nucleate pool boiling process for three surfactants solutions; TRITON X-100, SLES, and SDS. Each one is tested at concentrations; 0, 100, 400, 700, 1000, 1300, 1600 and $1900 \mathrm{ppm}$. Three heated horizontal tubes are tested that are made of Brass alloy C44400, Aluminum alloy 6061 and Stainless steel 316L.

2) For the investigated cases, the measured superheat temperatures and their corresponding heat flux and the surfactant concentration properties are fed into suitable published relations. That is to get correspondence between the bubble distribution and the thermal quantities.

3) From the resulting correspondence, we may suggest correlations for the heat flux, the superheat temperature, the surfactant concentration, and the bubble distribution for each surfactant solution

Table 1 illustrates the different investigated cases.

Table 1. The different investigated cases

\begin{tabular}{|c|c|c|}
\hline Brass Surface & Aluminum Surface & Stainless Steel Surfac \\
\hline Pure water & Pure water & Pure water \\
\hline $\begin{array}{c}\text { TRITON-X 100, } \\
100 \mathrm{ppm} .\end{array}$ & $\begin{array}{c}\text { TRITON-X 100, } \\
100 \mathrm{ppm} .\end{array}$ & $\begin{array}{c}\text { TRITON-X 100, } \\
100 \mathrm{ppm} .\end{array}$ \\
\hline $\begin{array}{l}\text { TRITON-X 100, } \\
400 \text { ppm. }\end{array}$ & $\begin{array}{l}\text { TRITON-X 100, } \\
400 \mathrm{ppm} .\end{array}$ & $\begin{array}{l}\text { TRITON-X 100, } \\
400 \mathrm{ppm} .\end{array}$ \\
\hline $\begin{array}{l}\text { TRITON-X 100, } \\
700 \text { ppm. }\end{array}$ & $\begin{array}{l}\text { TRITON-X 100, } \\
700 \text { ppm. }\end{array}$ & $\begin{array}{c}\text { TRITON-X 100, } \\
700 \mathrm{ppm} .\end{array}$ \\
\hline $\begin{array}{c}\text { TRITON-X 100, } \\
1000 \text { ppm. }\end{array}$ & $\begin{array}{c}\text { TRITON-X 100, } \\
1000 \mathrm{ppm} .\end{array}$ & $\begin{array}{c}\text { TRITON-X 100, } \\
1000 \mathrm{ppm} .\end{array}$ \\
\hline $\begin{array}{l}\text { TRITON-X 100, } \\
1300 \mathrm{ppm} .\end{array}$ & $\begin{array}{l}\text { TRITON-X 100, } \\
1300 \text { ppm. }\end{array}$ & $\begin{array}{l}\text { TRITON-X 100, } \\
1300 \text { ppm. }\end{array}$ \\
\hline $\begin{array}{c}\text { TRITON-X 100, } \\
1600 \text { ppm. }\end{array}$ & $\begin{array}{c}\text { TRITON-X 100, } \\
1600 \mathrm{ppm} .\end{array}$ & $\begin{array}{c}\text { TRITON-X 100, } \\
1600 \text { ppm. }\end{array}$ \\
\hline $\begin{array}{c}\text { TRITON-X 100, } \\
1900 \mathrm{ppm} .\end{array}$ & $\begin{array}{l}\text { TRITON-X 100, } \\
1900 \text { ppm. }\end{array}$ & $\begin{array}{c}\text { TRITON-X 100, } \\
1900 \mathrm{ppm} .\end{array}$ \\
\hline SLES, $100 \mathrm{ppm}$. & SLES, $100 \mathrm{ppm}$. & SLES, 100 ppm. \\
\hline SLES, $400 \mathrm{ppm}$. & SLES, $400 \mathrm{ppm}$. & SLES, $400 \mathrm{ppm}$. \\
\hline SLES, $700 \mathrm{ppm}$. & SLES, 700 ppm. & SLES, 700 ppm. \\
\hline SLES, $1000 \mathrm{ppm}$. & SLES, $1000 \mathrm{ppm}$. & SLES, $1000 \mathrm{ppm}$. \\
\hline SLES, $1300 \mathrm{ppm}$. & SLES, $1300 \mathrm{ppm}$. & SLES, $1300 \mathrm{ppm}$. \\
\hline SLES, $1600 \mathrm{ppm}$. & SLES, $1600 \mathrm{ppm}$. & SLES, $1600 \mathrm{ppm}$. \\
\hline SLES, $1900 \mathrm{ppm}$. & SLES, $1900 \mathrm{ppm}$. & SLES, $1900 \mathrm{ppm}$. \\
\hline SDS. 100 ppm. & SDS. 100 ppm. & SDS. $100 \mathrm{ppm}$. \\
\hline SDS. 400 ppm. & SDS. 400 ppm. & SDS. 400 ppm. \\
\hline SDS. 700 ppm. & SDS. 700 ppm. & SDS. 700 ppm. \\
\hline SDS. $1000 \mathrm{ppm}$. & SDS. 1000 ppm. & SDS. 1000 ppm. \\
\hline SDS. $1300 \mathrm{ppm}$. & SDS. $1300 \mathrm{ppm}$. & SDS. $1300 \mathrm{ppm}$. \\
\hline SDS. $1600 \mathrm{ppm}$. & SDS. $1600 \mathrm{ppm}$. & SDS. 1600 ppm. \\
\hline SDS. 1900 ppm. & SDS. $1900 \mathrm{ppm}$. & SDS. $1900 \mathrm{ppm}$. \\
\hline \multirow{2}{*}{ For Comparison } & TRITON-X. $500 \mathrm{ppm}$. & \\
\hline & SDS. 500 ppm. & \\
\hline
\end{tabular}

\section{EXPERIMENTAL SETUP}

\subsection{The test rig}

A controllable test rig was prepared and illustrated in Figure
1, (a more detailed fig. for the test rig is illustrated in Appendix A). This test rig consists of the following main components; The boiling and condensation vessel, figure A.2. consists of two stainless steel $(316 \mathrm{~L})$ hollow cylinders of different diameters connected by semi-conical shape $50 \mathrm{~mm}$ height. The upper cylinder has dimensions of $264 \mathrm{~mm}$ inner diameter, 280 $\mathrm{mm}$ outer diameter, and $200 \mathrm{~mm}$ length, and it contains a cooling coil, which is used in condensing the vapors of the aqueous solution. The lower cylinder has an inner diameter, outer diameter, and length of $150 \mathrm{~mm}, 166 \mathrm{~mm}$ and $200 \mathrm{~mm}$, respectively. It contains the figure A.3, the auxiliary heater, whose diameter and maximum power are $120 \mathrm{~mm}$ and $2 \mathrm{~kW}$, respectively, and a motor-driven stirrer. It has two glass windows (90 $\mathrm{mm}$ diameter each), which are perpendicular to each other, and whose center lines are at the level of $100 \mathrm{~mm}$ from the bottom. The vessel is well insulated by a $2 \mathrm{~cm}$ thickness layer of Polyurethane foam (Thermal conductivity is $\left.0.023 \mathrm{~W} \mathrm{~m}^{-1}{ }^{\circ} \mathrm{C}^{-1}\right)$. A pressure sensor is fitted to the top wall of the vessel. The test tube is fixed to the sidewall flange so that, they have the same centerline. The vessel bottom is equipped with a drainage port that discharges the required amount of the aqueous solution to the high concentration tank. Another sealed port surrounds the stirrer shaft, which has the same centerline as the auxiliary heater. Two temperature sensors are fitted to the inlet and outlet of the condensing coil. Another temperature sensor is located inside the vessel on the gas side, which monitors the saturation temperature. The three temperature sensors are interfaced to the computer through the NI USB 6210. The test tube (boiling surface) consists of a horizontal hollow tube (made of either brass, aluminum alloy 6061 or stainless steel 316L), whose outer diameter, inner diameter, and length are 26, 20, and $120 \mathrm{~mm}$, respectively. It contains an electric cartridge heater (100 mm long, $220 \mathrm{~V}$ and $1 \mathrm{~kW}$ ), whose insulated lead wires are press-fitted inside the tube using conductive grease. This grease fills any remaining air gaps and provides a good heat conductor. The heater is insulated from both ends to minimize the axial heat loss. The outer surface of each one of the three test tubes is treated mechanically by applying successive sandpapers with different roughness degrees; 400, 800, 1000, 1200, 1500, 2300, and 4000 grit. After that, the surface is polished with a polishing powder, cleaned with acetone, rinsed with a distilled water and dried by a hot dry air. The roughness of the three surfaces is then tested using a surface profile-meter, which checks the parameters $\mathrm{Ra}, \mathrm{Rq}, \mathrm{Rt}, \mathrm{Ry}$, and Rz, that are defined by DIN 4762 .

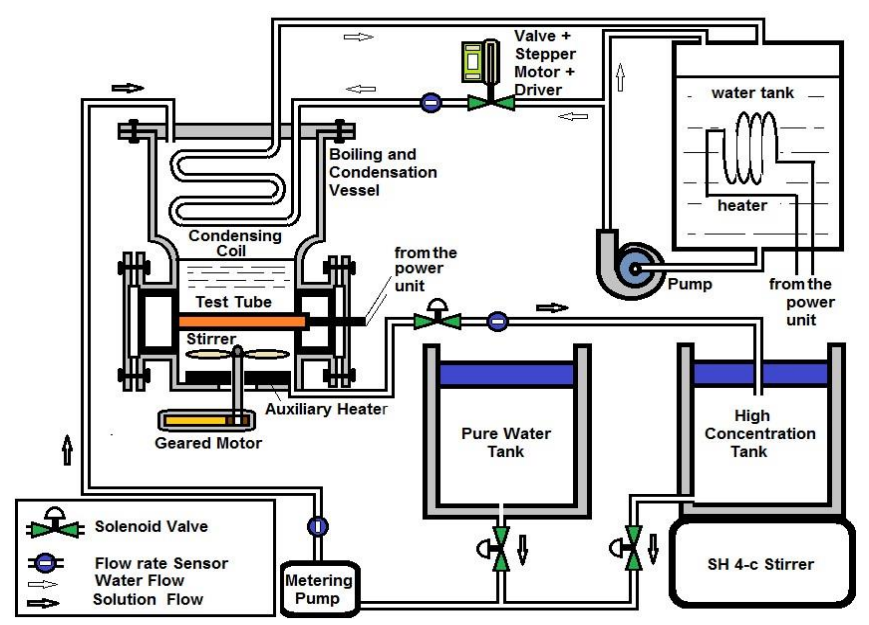

Figure 1. The experimental test rig 
Another four copper-constantan thermocouples are distributed around the tube to measure the liquid bulk temperature. The twelve thermocouples are connected to a data acquisition system that receives all their output signals and converts them into spreadsheets data. The cooling water circuit is used to absorb the boiling latent heat of the aqueous solution. This circuit works with the auxiliary heater to maintain the aqueous solution at constant saturation temperature under the saturation pressure. The water leaves the tank to the circulating pump which is of type Bosch PA66GF30 brushless and 17.5 liters/min. It supplies the condenser coil with the cooling water. The water rate is controlled by a valve that is driven by a stepper motor with its driver. The cooling water tank has a capacity of 80 liters and contains two ports on its top; one to receive the return water from the condensing coil, and the other is to receive the water from the bypass line. Another port is located in its bottom through which, the water is delivered to the circulating pump. The water temperature is monitored by a thermocouple that is interfaced to the computer through the acquisition unit. A 2 $\mathrm{kW}$ heater is switched $\mathrm{ON}$ when the temperature decreases below the required temperature. The high concentration tank has a capacity of ten liters and contains a surfactant aqueous solution of concentration $3000 \mathrm{ppm}$. This tank is used to supply the vessel with a high concentration aqueous solution to produce the required mixture concentration in the vessel. The solution, which is returned from the vessel enters the tank through a port in the top cover. The tank bottom includes a port through which, the aqueous solution can move to the metering pump. The tank is supported by a magnetic stirrer in order to ensure a uniform concentration during the experiment. The distilled water tank has a capacity of ten liters too and contains distilled water. This tank is used to supply the vessel with a distilled water to produce the required mixture concentration in the vessel. The required amount of distilled water leaves the tank to the metering pump through a port in the tank bottom. The cover on the top of any one of the last two tanks is capable of sliding vertically up and down to allow the inner space to expand or contract when it receives or supplies any amount of the aqueous solution. Also, the cover weight on the top of the liquid slightly increases the pressure inside the tank, and that aids the discharging process from the tank to the metering pump. Different measuring and control devices were used in the preparation of the experimental conditions for each run. The used controller is an 8051 Architecture Microcontrollers; a rich Atmel portfolio of MCUs based on the 8051 instruction set. The acquisition system is of type NI USB- 6210, input, 16- bit resolution and $256 \mathrm{ks} / \mathrm{s}$. The metering pump is WEA, HY Series with a diaphragm PTFE. Its frequency is from 0 to 160 Strokes/minute. It works at 230 -volt VAC $50 / 60 \mathrm{~Hz}$ and discharges from 0 to 3.0 Liters $/ \mathrm{min}$. Flow rate sensors of model FS 300 AG are fixed in the water and surfactant flow passages. Each one can read flow rates from 1 to $60 \mathrm{~L} / \mathrm{min}$. Four temperature sensors, of model TMP $36,10 \mathrm{mV} / 8^{\circ} \mathrm{C}$, are located in the water tank, the vessel and the condenser coil inlet and outlet ports. Twelve copper-constantan thermocouples with \pm 0.5 accuracies and are interfaced to an acquisition system. Eight thermocouples of them are distributed uniformly along the surface to measure the surface temperature. The other four thermocouples are distributed through the surfactant solution to measure its temperature. A valve that is controlled by a DC servo motor plus a National Instrument's (NI) DAQ Board, a lab view real-time software and the PCI extensions for instrumentation (PXI). A SKU237545 pressure transducer is located at the top of the condensation vessel. A magnetic stirrer Faithfulsh-4C Ceramic is used to ensure homogeneous surfactant concentration in the surfactant tank during the experiments.

\subsection{Experimental procedure}

Prior to performing the experiments, the test sections are cleaned routinely before the experiment with a sequence of operations involving washing with alcohol, rinsed with distilled water several times and dried by a supply of hot dry air. Then, the system is evacuated to a pressure of about 15 $\mathrm{mm} \mathrm{Hg}$. The test rig is considered valid if no leakage is detected over an interval of 24 hours. The detailed procedure is described in appendix ' $\mathrm{A}$ ';

\section{RESULTS AND ANALYSIS}

\subsection{Discussion of results}

The illustrated data were chosen from the experiments that are accomplished with the Aluminum tube. Figure 2 and 3 illustrate the variation of heat flux with the superheat temperature, $\Delta \mathrm{t}$, for TRITON and SDS surfactants at a concentration of $500 \mathrm{ppm}$. The illustrated data are from the present work and the work of both Elghanam [7] and Wen DS [13]. The used heating surface in the three cases are made of Aluminum. It is obvious that the present data are lower than those of [13]. This may be because, they used a horizontal plate and so, the buoyancy force assists all the bubbles that originate at the surface to be removed from the surface. These bubbles carry the majority of the heat transfer from the surface and its motions promote for the mixing processes. Also, the bubbles move away from the plate have lower possibilities of bubbles coalescence which produces larger bubbles. These large bubbles move upward at a lower velocity and impart the heat transfer process. In the case of horizontal tubes, the upper half of its narrow curved surface promotes for more bubbles coalescence and fewer bubble separations than those of the plate case.

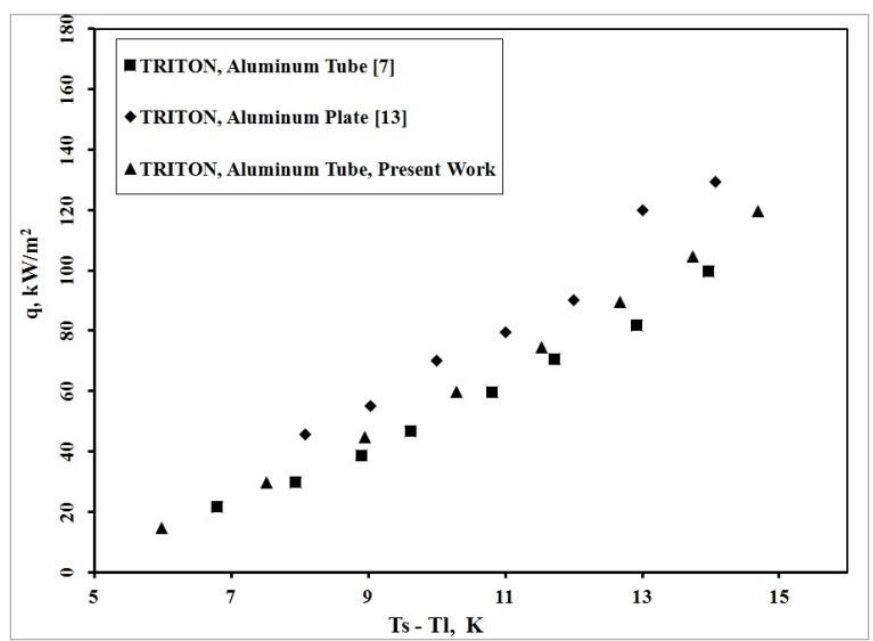

Figure 2. The variation of heat flux with $\Delta \mathrm{T}$ for TRITON surfactant at concentration of $500 \mathrm{ppm}$ from the present work and both Elghanam [7] and Wen DS [13] 


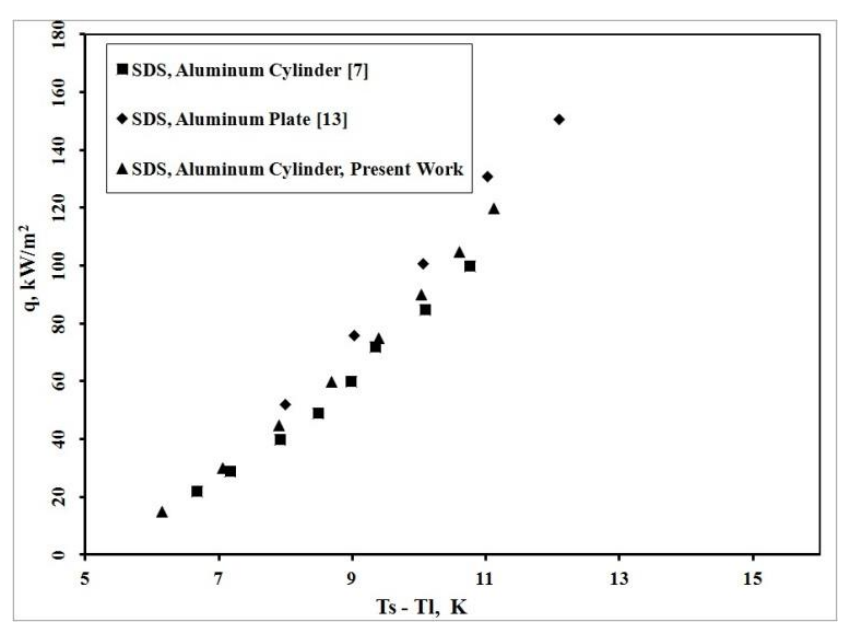

Figure 3. The variation of heat flux with $\Delta \mathrm{T}$ for SDS

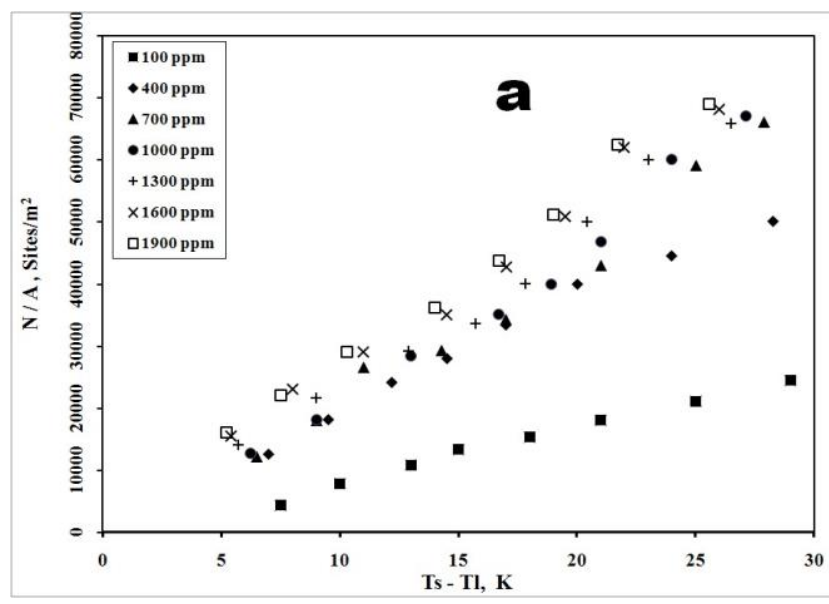

a) (N/A) with $(\Delta T)$ For TRITON

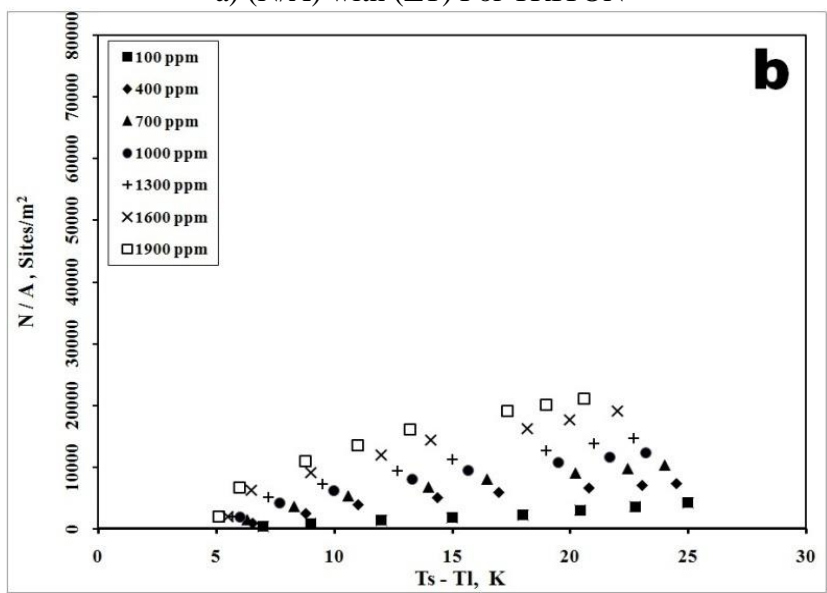

b) (N/A) with $(\Delta \mathrm{T})$ For SLES

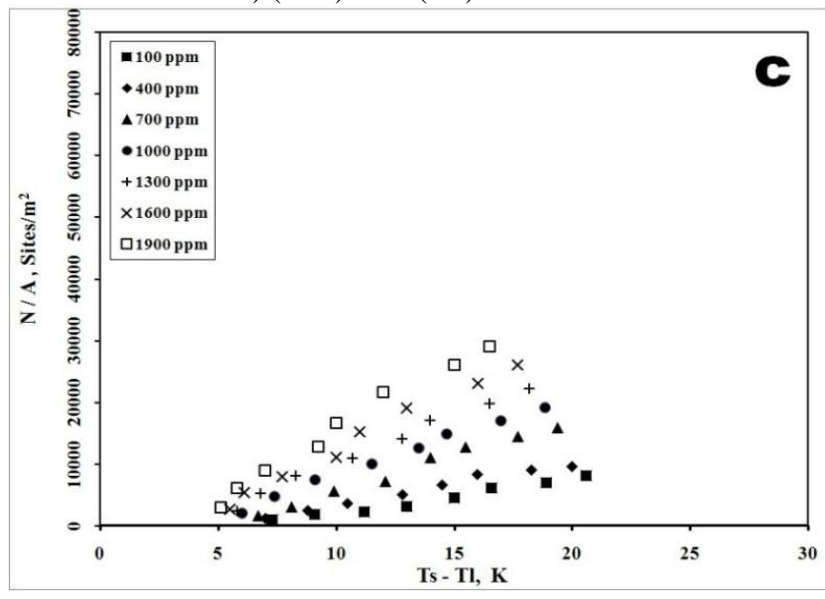

c) (N/A) with $(\Delta T)$ For SDS

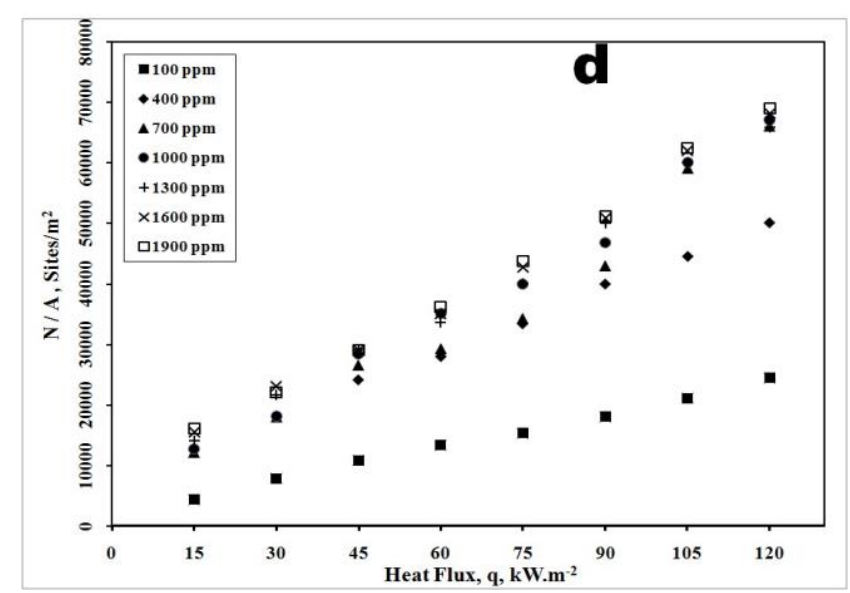

d) (N/A) With (q) For TRITON

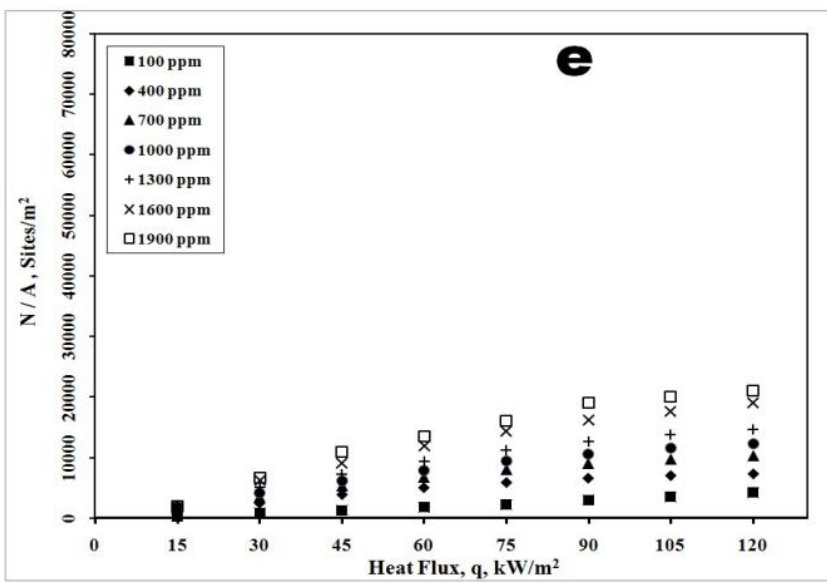

e) (N/A) With ( q) For SLES

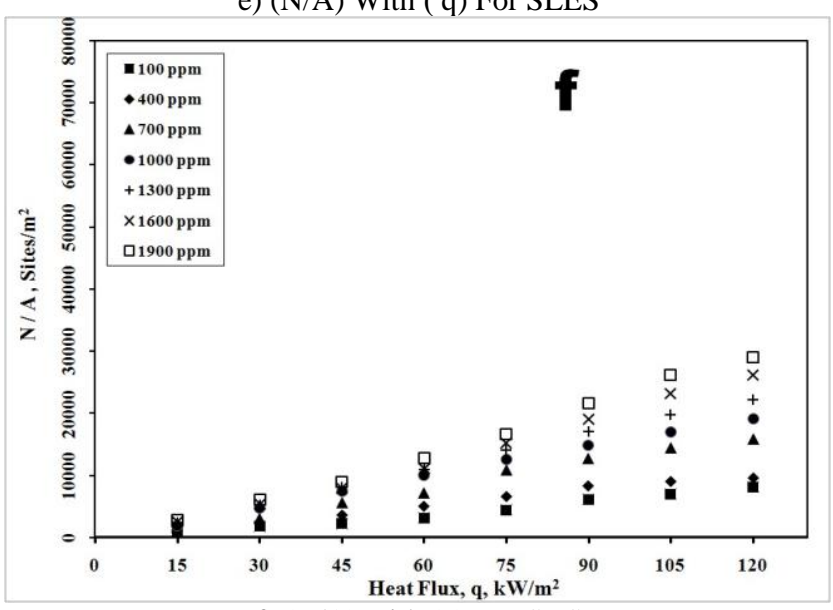

f) (N/A) with (q) For SDS

Figure 4. Variations of the bubble density with the heat flux and the superheat temperature

Surfactant at Concentration of $500 \mathrm{Ppm}$ from the Present work and both Elghanam [7] and Wen DS [13]. Figure 4 illustrates the variations of the bubble density with both; the heat flux and the superheat temperature for the three surfactants, TRITON, SLES, and SDS at different concentrations. From the figure, it is clear that, for all cases, the bubble density increased with both the heat flux and the superheat temperature. This may be interpreted by the increase in agitation effect resulted from the mobility of the bubbles leaving the tube surface. Also, the increase in bubbles activities; (frequency, growth, detaching and raising) promotes for higher turbulent activity and better mixing and transport processes, and consequently, more heat transfer. The 
increase in temperature gradients between the surface and the solution results in higher density and surface tension gradients. Accordingly, the characteristics of the interfacial region; (gassolid, gas-liquid and liquid-solid) changes to promote more bubble formation. Increasing the temperature gradient also results in enhancements of the buoyancy and Marangoni forces which, in turn, promote for more removed bubbles and more convective heat transfer. For the same superheat temperature, the bubble density increased with the surfactant concentration for all cases of SLES and SDS. For TRITON X100 , the rate of increase in the bubble density started to decay for concentration values higher than $400 \mathrm{ppm}$. For nucleate pool boiling in aqueous surfactant solutions, two primary interfaces have dominating influences. The first is the vaporliquid interface, at which the surface tension reduces because of the surfactant adsorption-desorption process. The second is the solid-liquid (or heater-liquid) interface, where the surfactant physisorption occurs and the surface wetting behavior changes. Surfactant additives in aqueous solutions naturally tend to diffuse towards the vapor-liquid interface and subsequently, they are adsorbed on it. Depending upon their chemistry (ionic and molecular structure) and orientation at the interface, some desorption may also occur. The primary effect of the surfactant adsorption-desorption process at the vapor-liquid interface is to reduce the surface tension of the solution, and accordingly, to facilitate the bubble formation and detaching.

When increasing the surfactant concentrations the surface tension reduces continually until the critical micelle concentration (CMC). Nonionic surfactant (TRITON X-100) has a relatively higher molecular weight and accordingly, its molecules diffuse slower than those of the other two surfactants. These molecules tend to cluster together to form micelles at a concentration which is lower than those of the other surfactants. So it shows higher, $\sigma$ relaxation and lowers CMC values than those of anionic surfactants (SLES and SDS) [7]. With TRITON X-100, the rate of increase in bubble distribution starts to decay at a lower concentration than those for the other surfactants. The entire process is time-dependent and it manifests in a dynamic surface tension behavior at an evolving vapor-liquid interface (as in ebullience), which eventually reduces to an equilibrium value after a long time span. The nucleation sites and the bubble frequency increase with the heat flux, which means shorter surface age. Accordingly, the majority of the bubble formation and detaching processes occur in a lower surface tension in the interface region and the possibilities of forming more new bubbles increase. With the increase of heat flux and the decrease of vapor density, these bubbles move faster by the buoyancy force beside the weak Marangoni forces. They participate considerably in the heat transport process and accordingly, help enhance the heat transfer. In addition, increasing the concentration of surfactant, TRITON X-100, which has higher molecular weight and lower diffusion capabilities, decreases the convective heat transfer, which helps the phase change to produce new bubbles.

It is observed in Figure 4 that, when increasing the heat flux and the superheat temperature, the rate of increase in the bubble density starts to decrease. That may be because increasing the heat flux results in more bubble formation and its increased mobility aids the thermal transport process. But the gaseous phase inside the growing bubbles has a lower thermal conductivity and this leads to a reduction in the heat transfer rate from the surface, and accordingly, a reduction in the possibilities of creating more nucleation sites. Figure 5 illustrates the effects of surfactant concentration on the size distribution function constants $\left(\mathrm{m}, \mathrm{Nmax} / \mathrm{A}\right.$, and $\left.\mathrm{r}_{\mathrm{st}}\right)$. When increasing the concentration of TRITON, " $\mathrm{m}$ " decreased slightly, " $\mathrm{N}_{\max }$ " increased, and $\mathrm{r}_{\mathrm{st}}$ decreased until the concentration values between 400 and 700 ppm and beyond this range, these three quantities varied asymptotically. For both SLES and SDS, " $m$ " kept decreasing slightly, " $\mathrm{N}_{\max }$ " kept increasing, and $\mathrm{r}_{\mathrm{st}}$ kept decreasing with the concentration.

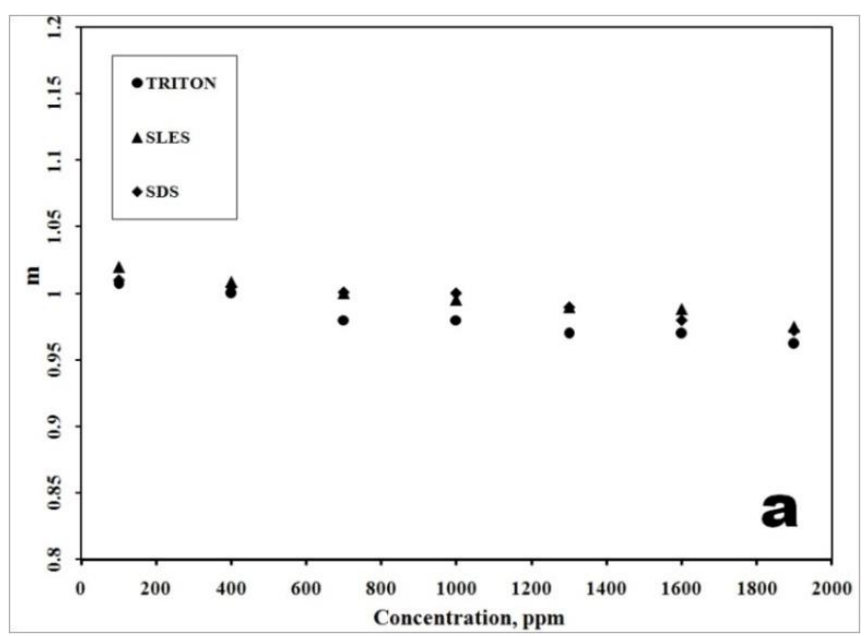

a) Variations of (m) with $\mathrm{C}$

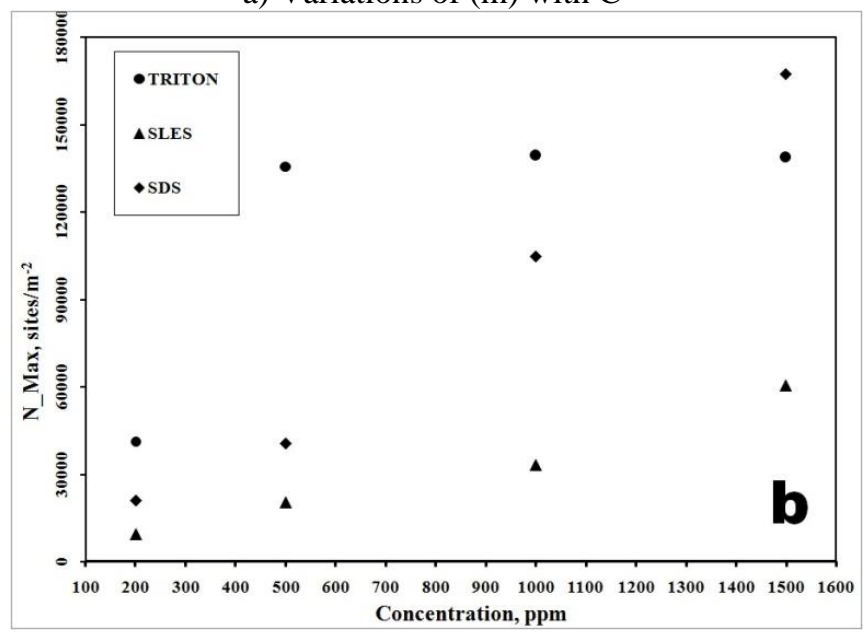

b) Variations of $\left(\mathrm{N}_{\max }\right)$ with $\mathrm{C}$

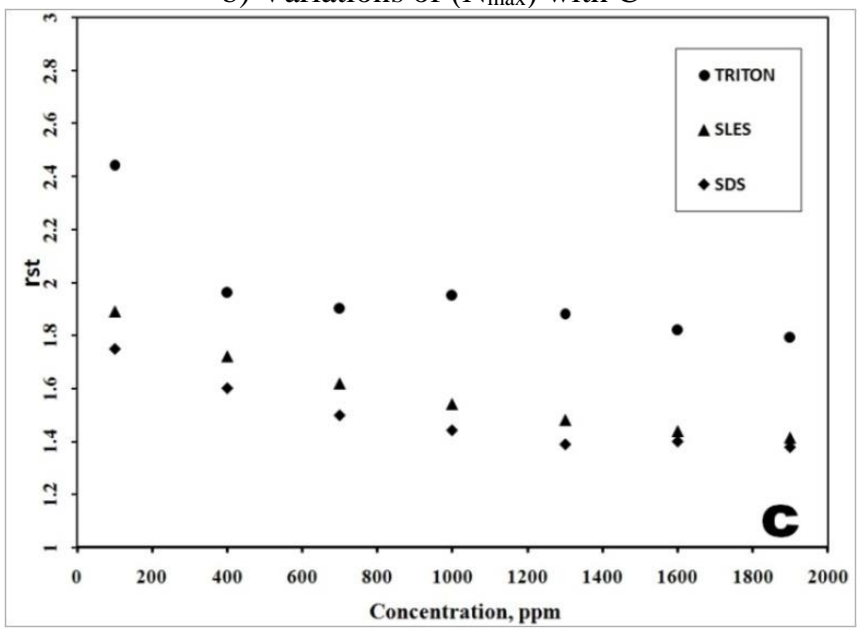

c) Variations of $\left(\mathrm{r}_{\mathrm{st}}\right)$ with $\mathrm{C}$

Figure 5. Variations of The Distribution Function Constants, $\mathrm{m}, \mathrm{N}_{\max }$ and $\mathrm{r}_{\mathrm{st}}$, With The Surfactant Concentration. 
As concluded before, adding surfactants to the pure water improves the heat transfer process. In other words, for the same heat flux, the superheat temperature difference will be lower than that for the pure liquid. Figure 6 illustrates the boiling behavior for the pure water and some aqueous solutions of surfactants.

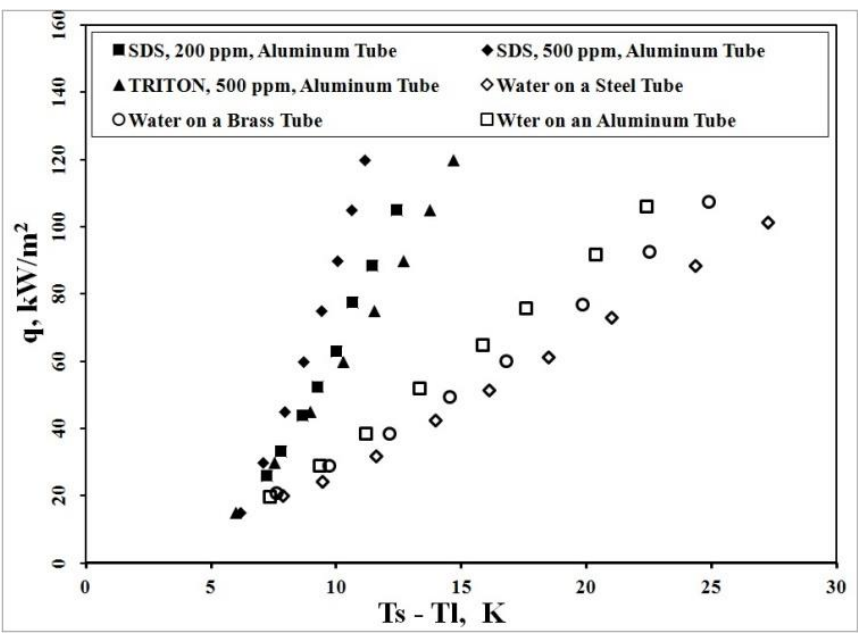

Figure 6. The variation of heat flux with the temperature difference for the pure water and some surfactant solutions

\subsection{Data analysis}

The mechanism of heat transfer enhancement during the nucleate boiling processes is complicated, and yet, it is difficult to model it exactly. So, some researchers tried to fit their experimental data into formulas that relate the bubble distribution to the superheat temperature and the liquid properties as follows;

According to [14];

$$
\frac{N}{A} \cdot \pi \cdot D_{b}^{2}=\frac{\left(h-h_{n c}\right)}{\left(h_{n u c}-h_{n c}\right)}
$$

N/A number of active nucleation sites per surface area

$\mathrm{D}_{\mathrm{b}}$, the diameter of the departed bubble which could be estimated using Fritz model [15] along with the estimated surfactant properties from [7];

$$
D_{b}=0.0208 \theta\left(\left(\sigma / g\left(\rho_{l}-\rho_{v}\right)\right)^{0.5}\right.
$$

where, for the mixture, $\theta$ equals 35

$\mathrm{h} \quad$ heat transfer coefficient for the whole area

$\mathrm{h}_{\mathrm{nc}} \quad$ convective heat transfer coefficient, and according to [16];

$$
\mathrm{h}_{\mathrm{nc}}=0.15\left[\left(\mathrm{~g}^{*} \beta^{*} \mathrm{C}_{\mathrm{l}}\left(\mathrm{p}_{\mathrm{l}}^{*} \lambda_{\mathrm{l}}\right)^{2}\right) / \eta\right]^{1 / 3} \Delta \mathrm{T}^{* 1 / 3}
$$

$\mathrm{h}_{\text {nuc }} \quad$ nucleate heat transfer coefficient;

$$
\mathrm{h}_{\text {nuc }}=1.1284\left[\left(\rho_{1} C_{1} \lambda_{1}\right)^{0.5^{*}} f^{0.5}\right.
$$

the bubble frequency, " $f$ " is calculated according;

$$
f=\left[\frac{0.314 g\left(\rho_{l}-\rho_{v}\right)}{D_{b} \rho_{l}}\right]^{0.5}
$$

The minimum cavity radius (critical radius), $r_{c}$, is calculated according to [7] and [14];

$$
r_{c}=\left[\frac{2 . T_{s a t}^{*} V_{f g} \sigma}{h_{f g} \rho \Delta T}\right]
$$

So, we may use the experimental data of the investigated cases of different heat fluxes, surfactant concentration, and heat fluxes, along with the surfactant solution properties [2] in order to calculate N/A and $r_{c}$ for different $\Delta T$ and accordingly, to relate N/A to $r_{c}$ as follows;

$$
\ln \left(\frac{N}{A}\right)=\ln \frac{N_{\max }}{A} \cdot\left(1-\left(\frac{r_{c}}{r_{s t}}\right)^{m}\right)
$$

where, Nmax is the maximum value of $\mathrm{N}$ ( $\mathrm{r}_{\mathrm{c}}$ approaching 0 ), $r_{s t}$ is the maximum value of $r_{c}$ which corresponds to the nucleation beginning $(\mathrm{N}=1)$, and $\mathrm{m}$ is an exponent. The values of $\mathrm{N}$ max, $\mathrm{r}_{\mathrm{st}}$, and $\mathrm{m}$ are experimentally determined and they depend mainly on the boiling fluid concentration. In the present work, the measured data for the aqueous surfactant solutions were fitted to these formulas in order to estimate correspondence between the superheat temperature and the bubble distribution. We already have the measured data for the heat flux and the superheat temperature. Accordingly, we could estimate correspondence between the heat flux in each case and the bubble distribution, the superheat temperature and the surfactant concentration. After testing many forms of correlations and analyzing the predicted results, it was possible to suggest the following correlations;

$$
q=a\left(T_{s}-T_{l}\right)^{b}(N / A)^{C}(C)^{d}
$$

for TRITON, $\mathbf{a}=\mathbf{0 . 0 0 3} b=\mathbf{1 . 1 2} c=\mathbf{0 . 2 5} \mathrm{d}=\mathbf{- \mathbf { 0 . 0 3 }}$

for CLES, $a=4 \times 10^{-8} b=0.69 \quad c=0.5 \quad d=-0.26$

for CDS, $\mathbf{a}=\mathbf{0 . 0 0 6} \quad b=\mathbf{0 . 5 0} \quad c=0.65 \quad d=\mathbf{- 0 . 2 4}$

Appendix (C) illustrates comparisons of the experimental data and those calculated from the correlations, equation (8). The maximum percentage of deviation of the calculated data using these correlations is about $5 \%$.

\section{CONCLUSION}

The objective of the present work is to achieve formulas that relates the heat flux to the bubble density, the superheat temperature, and the surfactant concentration in the pool boiling processes. First, we experimentally investigated the superheat temperatures and the corresponding heat flux in the pool boiling processes. The boiling liquids are three aqueous solutions of surfactants; SDS, SLES, and TRITON X-100 are investigated at concentrations of 0, 100, 400, 700, 1000, 1300, 1600 and $1900 \mathrm{ppm}$. The heating surfaces were Three tubes that are made of brass, aluminum, and stainless steel with almost the same surface roughness. The measured data along with the liquid properties for each surfactant were fed into formulas in order to estimate correspondence between the bubble distribution superheat temperatures. we suggested a formula to fit the data of these four quantities, the experimental results showed that, for all investigated cases, the bubble density increased with both the heat flux and superheat temperature. When increasing the surfactant concentration for 
the same heat flux, the bubble density increased for both SLES and SDS surfactants, but, for TRITON, the bubble density increased considerably until a concentration value between 400 and $700 \mathrm{ppm}$ and beyond this value, its rate of enhancement started to decrease. When increasing the surfactant concentration, the three distribution function constants varied as follows, for SLES and SDS, "m" slightly decreased, "Nmax" considerably increased, and " $r_{s t}$ " decreased. The same variations of the three constants occurred for TRITON until the concentration of $700 \mathrm{ppm}$, and beyond this value, the variations were asymptotical.

\section{REFERENCES}

[1] Hetsroni, G., Mosyak, A., Pogrebnyak, E. (2015). Effect of Marangoni flow on subcooled pool boiling on microscale and macro-scale heaters in water and surfactant solutions. International Journal of Heat and Mass Transfer, 89: 425-432. https://doi.org/10.1016/j.ijheatmasstransfer.2015.05.078

[2] Zhang, J.T. (2004). Experimental and computational study of nucleate pool boiling heat transfer in aqueous surfactant and polymer solutions. Ph.D. Thesis, Department of Mechanical, Industrial and Nuclear Engineering, University of Cincinnati.

[3] Manglik, R.M., Athavale, A., Kalaikadal, D.S., Deodhar, A., Verma, U. (2011). Reactor engineering: Multi-scale control and enhancement of reactor boiling heat flux by reagents and nanoparticles. Technical Report Tftpl-21Doe-Neer, August 2011, U.S. Department of Energy, University of Cincinnati, Cincinnati, Ohio 45221-0072.

[4] Inoue, T., Teruya, Y., Ishii, M., Monde, M. (2004). Enhancement of pool boiling heat transfer in water and ethanol/water mixtures (effect of surface-active agent). Heat Transfer-Asian Research, 33(4): 229-244. https://doi.org/10.1002/htj.20010

[5] Suryanarayana, G., Venkateswara Rao, G., Balakrishna, N. (2015). Experimental investigation on pool boiling heat transfer with sodium dodecyl sulfate. International Journal of Mechanical Engineering and Computer Applications, 3(2): 32-37.

[6] Hetsroni, G., Zakin, J.L., Lin, Z., Mosyak, A., Pancallo, E.A., Rozenblit, R. (2001). The effect of surfactants on bubble growth, wall thermal patterns and heat transfer in pool boiling. International Journal of Heat and Mass Transfer, 44(2): 485-497. https://doi.org/10.1016/S00179310(00)00099-5

[7] Elghanam, R.I., Fawal, M.M.EL., Abdel Aziz, R., Skr, M.H., Hamza Khalifa, A. (2011). Experimental study of nucleate boiling heat transfer enhancement by using surfactant. Ain Shams Engineering Journal, 2(3-4): 195209. https://doi.org/10.1016/j.asej.2011.09.001

[8] Hao, P., Ding, G.L., Hu, H.T. (2011). Effect of surfactant additives on nucleate pool boiling heat transfer of refrigerant-based nanofluid. Experimental Thermal and Fluid Science, $\quad 35(6)$ : $\quad 960-970$. https://doi.org/10.1016/j.expthermflusci.2011.01.016

[9] Xia, G.D., Jiang, H.M., Liu, R., Zhai, Y.L. (2014). Effects of surfactant on the stability and thermal conductivity of $\mathrm{Al}_{2} \mathrm{O}_{3} /$ de-ionized water nanofluids. International Journal of Thermal Sciences, 84: 118-124. https://doi.org/10.1016/j.ijthermalsci.2014.05.004

[10] Qasim, B., Al-Sukhani, A. (2014). Enhancement techniques for boiling heat transfer. Ms.C Thesis, the College of Engineering, Department of Mechanical Engineering, Embry-Riddle Aeronautical University, Daytona Beach, Florida, November.

[11] Hu, Z.C. (2011). Pool boiling heat transfer of aqueous surfactant solutions. 28-29 March 2011, Added to IEEE Xplore: 15 April.

[12] Raza, M.Q., Kumar, N., Raj, R. (2016). Surfactants for bubble removal against buoyancy. Scientific RepoRts, 6: 19113. https://doi.org/10.1038/srep19113

[13] Wen, D.S., Wang, B.X. (2002). Effects of surface wettability on nucleate pool boiling heat transfer for surfactant solutions. Int J Heat Mass Trans., 45(8): 173947. https://doi.org/10.1016/S0017-9310(01)00251-4

[14] Griffith, P., Wallis, J.D. (1960). The role of surface conditions in nucleate boiling. Chemical Engineering Progress Symposium Series, 56(30): 49-63.

[15] Fritz, W. (1935). Berechnung des Maximal volumens von Dampfblasen. Phys. Z., 36: 379384.

[16] Han, C. Y., Griffith, P. (1965). The mechanism of heat transfer in nucleate pool boiling. Int J Heat Mass Trans., 8(6): $\quad 887-914 . \quad$ https://doi.org/10.1016/00179310(65)90073-6

\section{NOMENCLATURE AND ABBREVIATIONS}

\section{Alphabetic}

A The heated area of the test tube, $\mathrm{m}^{2}$.

c Concentration, ppm.

$\mathrm{c}_{1} \quad$ Liquid specific heat, $\mathrm{kJ} /(\mathrm{kg} . \mathrm{K})$.

$\mathrm{D}_{\mathrm{b}} \quad$ Bubble diameter, $\mathrm{m}$.

$f \quad$ Bubble frequency, $1 / \mathrm{s}$.

g Gravitational acceleration, $\mathrm{m} / \mathrm{s}^{2}$.

$\mathrm{h} \quad$ Heat transfer coefficient of the surfactant solution, $\mathrm{W} /\left(\mathrm{m}^{2} . \mathrm{K}\right)$.

I Current, amp.

$\mathrm{m} \quad$ Exponent of the distribution function

$\mathrm{N} \quad$ Number of active nucleation sites

$\mathrm{N}(\mathrm{r}) \quad$ Distribution function for the radii of stable nuclei

$\mathrm{p} \quad$ Pressure, $\mathrm{N} / \mathrm{m}^{2}$.

q Heat flux, $\mathrm{W} / \mathrm{m}^{2}$.

$\mathrm{r} \quad$ Bubble radius, $\mathrm{m}$.

$r_{\mathrm{st}} \quad$ Maximum value of $(\mathrm{r})$; which corresponds to the nucleation starting $(\mathrm{N}=1)$, $\mathrm{m}$.

$R_{\mathrm{a}}, \mathrm{R}_{\mathrm{q}}, \mathrm{R}_{\mathrm{t}}, \mathrm{R}_{\mathrm{y}}$ and $\mathrm{R}_{\mathrm{z}} \quad$ surface roughness parameters defined by DIN $4762 \mu \mathrm{m}$.

$r_{c} \quad$ Minimum radius of nucleation sites, $m$.

$\mathrm{T} \quad$ Fluid temperature, $\mathrm{K}$.

V Voltage, Volts.

\section{Greek symbols}

$\theta \quad$ Contact angle, degrees.

$\eta \quad$ Dynamic viscosity, N.s $/ \mathrm{m}^{2}$.

$\lambda \quad$ Liquid thermal conductivity, $\mathrm{W} /\left(\mathrm{m}^{2} . \mathrm{K}\right)$

$\rho \quad$ Mass density, $\mathrm{kg} / \mathrm{m}^{3}$.

$\sigma \quad$ Surface tension of liquid-vapor interface, $\mathrm{N} / \mathrm{m}$.

\section{Subscripts}

b Bubble leaving the heated surface.

c Surface cavity. 
fg variation during phase change.

$1 \quad$ Saturated liquid.

max Maximum number of active nucleation sites.

nc Natural convection.

nuc Nucleation.

$\mathrm{s}$

sat

$\mathrm{v}$

W

\section{Abbreviations}

DAQ Data acquisition.

PID Proportional, Integral, and Differential.

SDS Sodium dodecyl sulfate.

SLES Sodium lauryl ether sulfate.

TRITON-X 100 Octyl phenol ethoxylate with 9-10 moles of ethylene oxide.

\section{APPENDIX A. Detailed Experimental Procedure}

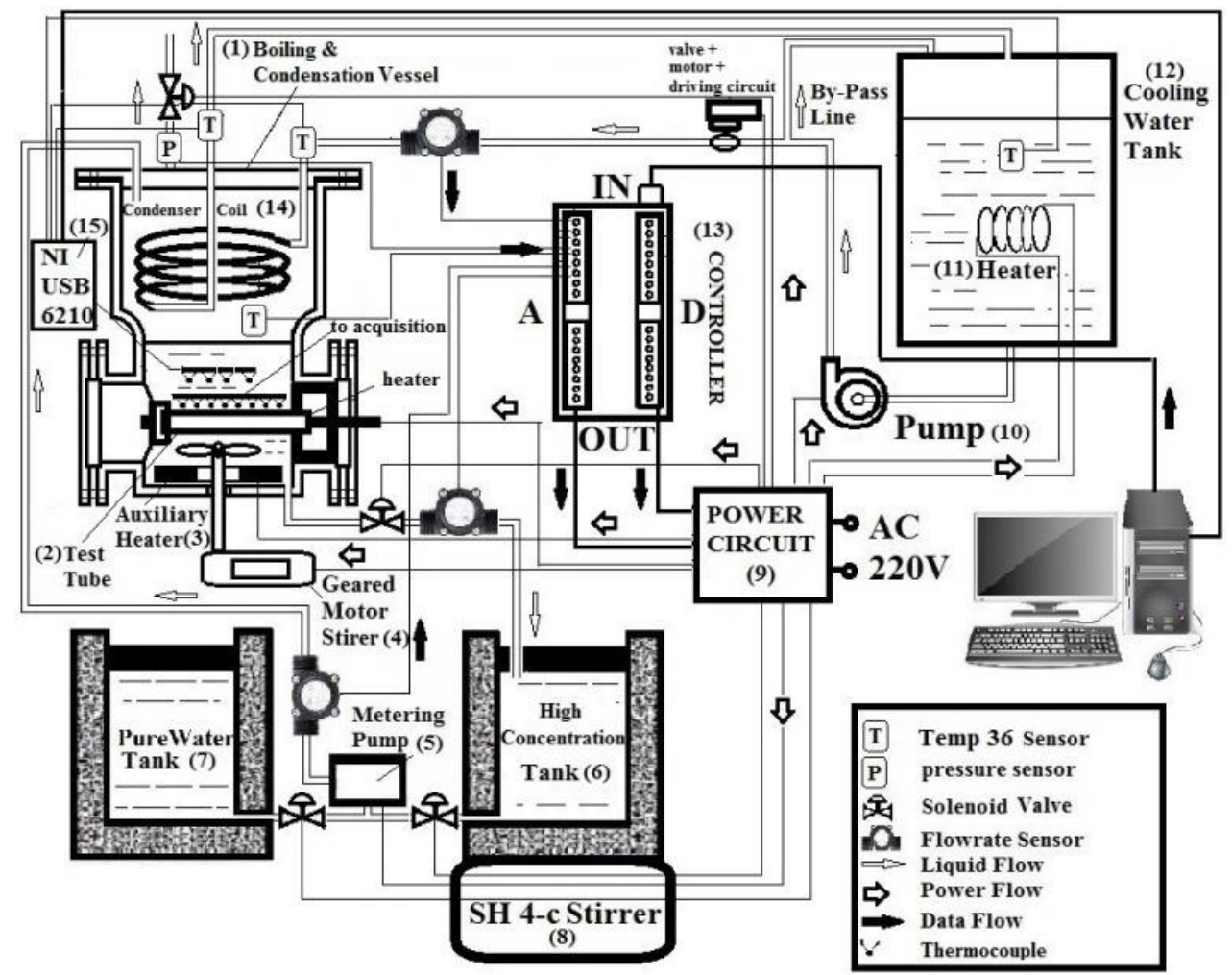

Figure A.1. The detailed drawing of the test rig
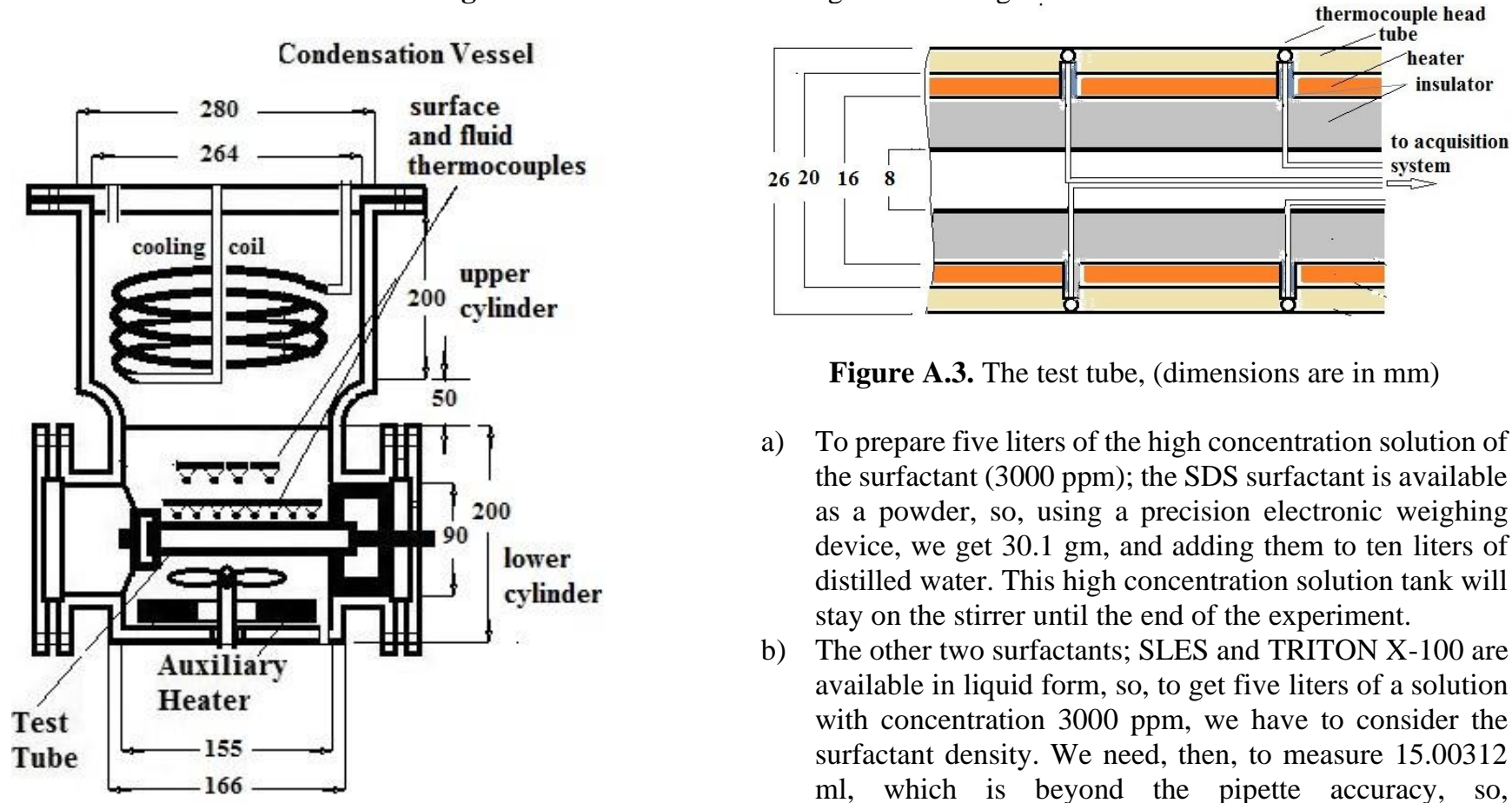

Figure A.3. The test tube, (dimensions are in $\mathrm{mm}$ )

a) To prepare five liters of the high concentration solution of the surfactant (3000 ppm); the SDS surfactant is available as a powder, so, using a precision electronic weighing device, we get $30.1 \mathrm{gm}$, and adding them to ten liters of distilled water. This high concentration solution tank will stay on the stirrer until the end of the experiment.

b) The other two surfactants; SLES and TRITON X-100 are available in liquid form, so, to get five liters of a solution with concentration $3000 \mathrm{ppm}$, we have to consider the surfactant density. We need, then, to measure 15.00312 $\mathrm{ml}$, which is beyond the pipette accuracy, so, approximating the amount to $15.003 \mathrm{ml}$ will not considerably affect the concentration accuracy. Adding 
this amount to five liters of distilled water to get the high concentration solution (approximately $3000 \mathrm{ppm}$ )

c) To remove the dissolved non-condensable gases, the high concentration solution is delivered to a separate container, which includes a variable power electric heater, digital thermometer, and an adjustable check pressure valve. The heater is operated at a power of about $1375 \mathrm{~W}$ to heat the solution under atmospheric pressure. After boiling the solution, the heater is kept working for one hour, and During this process, the check valve maintains the pressure at atmospheric value. The heater power is then reduced gradually until the temperature is near the saturation value and then, is maintained for about 45 minutes, Elghanam [7]. Now, the test rig is ready to start the experiment.

d) After installing the test tube, the vessel is charged with three liters of the distilled water to a level of about 120 $\mathrm{mm}$ above the top of the test tube surface.

e) The controller starts the experiment by increasing the power supplied to the auxiliary heater from zero to its maximum by the gradual increase of the MPW signal, which is sent to the power unit. After achieving the maximum power, the heater keeps working until the temperature sensor indicates the saturation value. The controller is programmed to allow ten seconds delay between any two successive readings for either the pressure or the temperature

sensors inside the vessel in order to ensure a correct sense of the trend of change in these quantities.

f) During the heating of the water, the controller keeps reading the pressure and temperature sensors inside the vessel. If the pressure exceeds the atmospheric value, and the temperature is still below the saturation value, that corresponds to the atmospheric pressure, the controller sends a digital signal to the power unit to open the solenoid valve in the vessel until retrieving the atmospheric value. If the temperature inside the vessel started to exceed the saturation, that corresponds to the atmospheric pressure, the controller does not allow the solenoid valve to open, even if the pressure exceeded the atmospheric pressure value because this increase is caused by the increase in temperature above the saturation value. In such case, the program switches the auxiliary heater off and signals the power unit to operate the circulating pump until retrieving the saturation temperature again.

g) Although the vessel is well isolated but still looses heat to the low-temperature surrounding, these unpredicted losses constitute a steady disturbance to the temperature. So, the controller always uses the decrease in vessel temperature below the saturation temperature as a feedback to a PID technique, that determines the correction in MPW of the signals. These signals are sent to the power unit which determines the required power supplied to the water valve and the auxiliary heater, which will maintain a saturation temperature value inside the vessel.

h) The steady values for both the atmospheric pressure and its corresponding temperature are recognized, when the percentage of the difference between any two successive readings of at least five successive readings lies within the range of $\mp 1 \%$ of the preceding value. After achieving the steady state, the controller then, sends two analog signals to the power unit, the first is to supply the test tube heater with about124.3 Watts, which corresponds to a heat flux of $15 \mathrm{~kW} / \mathrm{m}^{2}$, and the second is to supply the circulating pump with a power, that corresponds to a discharge, D, where;

$$
\mathrm{D}=\mathrm{V}^{2} / \mathrm{R} \cdot\left[\rho \mathrm{c}\left(\mathrm{T}_{\mathrm{in}}-\mathrm{T}_{\mathrm{o}}\right)\right]_{\mathrm{w}}
$$

$\mathrm{V}$ is the voltage that is applied to the tube heater to produces the required heat flux and $\mathrm{R}$ is the heater resistance. $T_{\text {in }}$ and $T_{o}$ are the inlet and outlet cooling water temperatures. The cooling water is supplied to the vessel to absorb the tube heater energy to help maintain a steady state. The pressure adjustment procedure, that is mentioned above, is still operated until achieving almost a steady state pressure and the temperature inside the vessel, with a tolerance within the value of $\mp 1 \%$.

i) The program compares the temperature reading of each one of the twelve thermocouples with its previous one. It does not record any temperature reading unless it achieves its steady state condition, which is recognized by the same criteria, which is mentioned above. And it calculates the heat flux, the surface, and liquid temperatures according to;

$$
\begin{aligned}
& \mathrm{q} \mathrm{s}_{\mathrm{s}}=\mathrm{V}^{2} /\left(\mathrm{R} \cdot \mathrm{A}_{\mathrm{s}}\right) \\
& \mathrm{T}_{\mathrm{s}}=\sum_{i=1}^{i=8} T_{i} / 8 \\
& \mathrm{~T}_{\mathrm{L}}=\sum_{i=1}^{i=4} T_{i} / 4
\end{aligned}
$$

j) When the temperature sensors inside the vessel and in the inlet and outlet ports of the cooling water circuit indicates steady readings according to the criteria, that is mentioned above, the controller then makes 10 minutes delay to ensure that, the acquisition system has recorded the steady readings. Then, the controller starts a new run with a new predetermined heat flux, which exceeds the previous value by 124.3 Watts. And the steps from 4 to 9 are repeated until achieving a heat flux of $120 \mathrm{~kW} / \mathrm{m}^{2}$, then, the first experiment group is accomplished.

k) The current values of the surfactant concentrations in both the vessel and the high concentration tank, fig. 1, are zero and $3000 \mathrm{ppm}$, respectively. To start a new group with a new surfactant concentration in the vessel, the new surfactant concentration in the high concentration tank must be calculated and updated by the controller, as follows;

The controller opens the pressure port in the vessel top cover to compensate for any change in the pressure during the change process. It opens the port in the vessel bottom to discharge the vessel solution for a period of time, $t 1$. This time is required by the vessel to discharge an amount of solution, $m$, to the high concentration tank. This time period is estimated as follow;

$$
\begin{gathered}
\mathrm{t}_{1}=\mathrm{m} / \mathrm{D}_{\mathrm{vh} 1} \\
m=\frac{15\left(C_{v, \text { old }}-C_{v, \text { new }}\right)}{\left[3\left(C_{v, \text { new }}-C_{v, \text { old }}\right)+5\left(C_{v, \text { old }}-C_{h, \text { old }}\right)\right]}
\end{gathered}
$$

$C_{v, \text { old }} \quad$ the old value of liquid concentration inside the vessel (before each mixing process) (initially, equals 100 ppm)

$C_{v \text {,new }}$ the required new value of liquid concentration inside 
the vessel (after each mixing process)

$C_{h, o l d}$ the old value of liquid concentration inside the high concentration tank (before each mixing process) (initially, equals $3000 \mathrm{ppm}$ )

$\mathrm{D}_{\mathrm{vh} 1}$ discharge from the vessel to the high concentration tank, and, it is monitored by the controller through a mass flow rate sensor.

The controller then switches the vessel valve off and opens the high concentration tank valve on. It then operates the metering pump to supply the same amount, $m$, from the high concentration solution to the vessel. The metering pump works for a time period, $\mathrm{t}_{2}$, where;

$$
\mathrm{t}_{2}=\mathrm{m} / \mathrm{D}_{\mathrm{vh} 2}
$$

$\mathrm{D}_{\mathrm{vh} 2}$ is the discharge from the high concentration tank to the vessel and, it is monitored by the controller through another mass flow rate sensor. During this process, the motor stirrer is operated and keeps working after the mixing process for five minutes, until the controller switches it off.

1) The changeover from one aqueous surfactant solution to the other must be preceded by a reliable cleaning protocol for ensuring that there are no remaining remnants of the earlier sample inside the boiling condensation vessel. This is achieved by the three-cycle operation of cleaning/rinsing with distilled water, acetone, and ethanol, and vacuum drying.

m) The steps from 4 to 12 are repeated until accomplishing the experiments for the three surfactant types besides those of the distilled water

\section{APPENDIX B. Error Analysis}

In the present work, the basic measured values are the superheat temperature and the heat transfer, and so the estimated errors may be as follows;

To estimate the uncertainties of the derived quantities, $\delta \mathrm{A}$, $\delta \mathrm{T}$ and $\delta \mathrm{h}$, we first calculate the uncertainties of the participating quantities, which are;

The Length: is measured using a vernier caliper with uncertainty $0.02 \mathrm{~mm}$

The temperature that is used in calculating the heat flux is measured by copper-constantan thermocouples. This type has an accuracy of $\pm 0.5{ }^{\circ} \mathrm{C}$

Then, we can estimate the uncertainties in the derived quantities as follows;

$$
\begin{gathered}
\delta A=(\pi d l) \sqrt{\left(\frac{\delta d}{d}\right)^{2}+\left(\frac{\delta l}{l}\right)^{2}} \\
\delta Q=(98.3 / 100) x V \times I \sqrt{\left(\frac{\delta V}{V}\right)^{2}+\left(\frac{\delta I}{I}\right)^{2}} \\
\delta q=\frac{Q}{A} \sqrt{\left(\frac{\delta Q}{Q}\right)^{2}+\left(\frac{\delta A}{A}\right)^{2}}
\end{gathered}
$$

The error in the heat transfer in equation (1) is estimated as follows;

$$
\delta h=\frac{Q}{A\left(T_{s, a v}-T_{l}\right)} \sqrt{\left(\frac{\delta Q}{Q}\right)^{2}+\left(\frac{\delta A}{A}\right)^{2}+\frac{\delta T_{s, a v}{ }^{2}+\delta T_{l}^{2}}{\left(T_{s, a v}-T_{r, a v}\right)^{2}}}
$$

\begin{tabular}{|c|c|c|c|c|c|}
\hline \multicolumn{2}{|c|}{ TRITON X-100 } & \multicolumn{2}{|c|}{ SLES } & \multicolumn{2}{|l|}{ SDS } \\
\hline Corr. Exp. & Err.\% & Corr.Exp. & Err.\% & Corr.Exp. & Err.\% \\
\hline 283 & 54 & $0 \Omega 8$ & 007 & 74275 & 00 \\
\hline 20.0 & & & & (5. & 40 \\
\hline 100.9105 & -3.8 & 106.1105 & 1.09 & 15.015 & 0.53 \\
\hline 123.6120 & 3.0 & 124.0120 & 3.36 & 43.745 & -2.78 \\
\hline 31.4730 & 4.9 & 106.0105 & 1.03 & 93.790 & 4.18 \\
\hline $44.68 \quad 45$ & -0.7 & $46.41 \quad 45$ & 3.1 & 108. 105 & 3.2 \\
\hline 87.9890 & -2.2 & $77.87 \quad 75$ & 3.8 & 120.712 & 0.6 \\
\hline 110.7105 & 5.4 & 106.210 & 51.2 & $46.7 \quad 45$ & 3.90 \\
\hline 29.0230 & -3.2 & 30.1930 & 0.6 & $79.3 \quad 75$ & 5.73 \\
\hline 92.7990 & 3.1 & $44.06 \quad 45$ & -2.1 & $92.3 \quad 90$ & 2.64 \\
\hline 110.9105 & 5.6 & 60.8460 & 1.4 & 108.5105 & 3.41 \\
\hline 28.7130 & -4.3 & 74.4175 & -0.8 & $123.1 \quad 12$ & 2.6 \\
\hline 93.6090 & 4.0 & 91.9690 & 2.1 & 30.0530 & 0.19 \\
\hline $15.7 \quad 15$ & 4.7 & 103.410 & -1.5 & 44.1345 & -1.91 \\
\hline $29.7 \quad 30$ & -0.9 & 29.8030 & -0.65 & 60.5960 & 0.99 \\
\hline 61.760 & 2.9 & 59.8460 & -0.25 & 77.9475 & 3.92 \\
\hline 15.0115 & 0.08 & 73.3975 & -2.13 & 92.7790 & 3.08 \\
\hline 102.3105 & -2.6 & 92.0690 & 2.3 & 110.4105 & 5.15 \\
\hline 117.4120 & -2.1 & 103.110 & -1.8 & $125.2 \quad 120$ & 4.4 \\
\hline
\end{tabular}

The worst relative errors in the heat flux, $\delta \mathrm{q}$, was about $4.28 \%$.

\section{APPENDIX C. Tests of Correlation Equation 8}

